Background/introduction A large GUM clinic introduced a sexual assault pro forma to improve the management of patients alleging sexual assault.

Aim(s)/objectives To compare standard of care of complainants of sexual assault with and without use of pro forma.

Methods A retrospective review of patient records with evidence of first disclosure of sexual assault was undertaken for an eight month period. Data on 16 outcomes including 14 nationally auditable standards was analysed against use of the pro forma. Data analysis was performed using Stata. Data collection will be extended to twelve months.

Results 65 patients were included. A pro forma was only completed in 58\%. The following outcomes were significantly associated with pro forma use: HIV risk assessment $(p=<0.001)$, detailed history of assault ( $p=<0.001$ ), offer of hepatitis B vaccine $(p=0.03)$ and completion of self-harm assessment $(p=<0.001)$. Other outcomes supporting pro forma use were risk assessment of vulnerability $(p=<0.001)$ and offer of psychological support $(p=<0.001)$. STI testing specifically for hepatitis $\mathrm{C}$ and trichomonas vaginalis was below the national auditable standard in both groups.

Discussion/conclusion The use of a pro forma has improved clinical care of complainants of sexual assault. Poor uptake of use of the pro forma within the clinic needs to be addressed. Amendments to the pro forma may improve outcomes such as increasing offer of testing for hepatitis $\mathrm{C}$ and trichomonas vaginalis.

\section{P131 MANAGEMENT OF SEXUAL ASSAULT IN A COUNTY- WIDE INTEGRATED SEXUAL HEALTH SERVICE: INFREQUENTLY REPORTED BUT COMPLEX NEEDS IDENTIFIED}

${ }^{1}$ Nicola Wallis, ${ }^{2}$ Sue Ralph, ${ }^{2}$ Alison Wardropper, ${ }^{2}$ Conrad White, ${ }^{2}$ Sarah Duncan ${ }^{1}$ University of Newcastle Medical School, Newcastle, UK; ${ }^{2}$ County Durham and Darlington NHS Foundation Trust Sexual Health Service, County Durham and Darlington, UK

\subsection{6/sextrans-2015-052126.174}

Background/introduction County Durham and Darlington NHS Foundation Trust (CDDFT) recently published local standards of care for patients disclosing sexual assault within the sexual health service. CDDFT is the sole provider of sexual health services throughout the county, offering fully integrated GUM, Family Planning and HIV clinics.

Aim(s)/objectives This study aims describe the current management of sexual assault within CDDFT Sexual Health Services.

Methods Patients who disclosed an alleged sexual assault from 01.01.2014-31.12.2014 were identified by local electronic codes and retrospective case note review was performed. Summary statistics were calculated using STATA v 11.0 and means/percentages presented as appropriate.

Results Of 55 patients reporting alleged sexual assault, 44 case notes were available for review (80\%). 39 patients were female $(89 \%)$ and 5 were male $(11 \%)$ with a similar mean age of 24.5 years. Police involvement was equally prevalent in patients reporting recent verses historical sexual assault (18/28 (64\%) v $9 / 16(56 \%) \mathrm{p}=0.52)$ and incident details were recorded in all cases where police referral was declined (17/17, 100\%). 39/44 patients accepted STI screening, 7/44 patients were at risk of unwanted pregnancy and accepted emergency contraception;
12/44 patients were offered prophylactic antibiotics and 24/44 were offered Hep B vaccination; 6/44 patients commenced PEP and 6/8 under 18 year olds were referred to local safeguarding teams.

Discussion/conclusion Patients reporting alleged sexual assault were seen infrequently but often had complex needs. Implementing new local policy with strengthen our ability to identify these patients and standardise our approach to management.

\section{P132 "WHAT DO I DO WITH MY VIBRATOR DOCTOR?"}

Daisy Ogbonmwan*, Stephen Bushby. Department of GUM, Sunderland Royal Hospital, Sunderland, UK

\subsection{6/sextrans-2015-052126.175}

Background/introduction The use of sex toys is common amongst same sex relations and heterosexuals. Evidence exists that sex toys can be a method of transmission for many sexually transmitted infections (STI). Literature from BASHH and FSRH are explicit in recognising this and it is therefore important that we discuss the importance of safe sex toy use with our patients. Aim(s)/objectives Our aims were to assess whether clinicians routinely discussed the use of sex toys; if so with whom and whether advice was routinely given post diagnosis of an STI.

Methods A survey was designed and sent to local sexual health clinics. Responses were anonymous, using a web site link. Respondents were asked, amongst other questions, if they routinely discussed sex toy usage with their patients and if so when and with whom; and what advice was given regarding sex toy usage post diagnosis of an STI.

Results Responses were received mostly from consultants and specialist nurses. 25\% regularly discussed sex toys largely during safe sex discussions. Respondents felt women who have sex with women and men who have sex with men (94\%, 84\% respectively) benefitted most from this discussion. $22 \%$ discussed possible STI transmission with sex toys; however $88 \%$ did not routinely give advice post STI diagnosis.

Discussion/conclusion Results show that despite evidence there is limited discussion regarding safe sex with sex toys in this group of clinicians. This could lead to unawareness amongst our patient population and unnecessary transmission of infection. To improve this, education is to be undertaken via our regional BASHH meeting.

\section{P133 THE EFFECT OF INTRODUCING ROUTINE SELF-TAKEN EXTRA-GENITAL SWABS IN A GUM CLINIC COHORT}

Farai Nyatsanza*, Anisha Trivedy, Gary Brook. Central Middlesex Hospital, London, UK

\subsection{6/sextrans-2015-052126.176}

Background Starting July 2013, self-taken extra-genital swabs were offered routinely to all patients attending the department. Aim To assess detection of extra-genital infection since introduction of self-taken swabs.

Methods We compared patients diagnosed with Chlamydia and Gonorrhoea in the 6-month period before (February-July 2012) and after (February-July 2014) the introduction of self-taken extra-genital swabs. The rate of self-swabbing was determined in separate consecutive groups of 100 patients who had extragenital swabs in the same periods. 
Results There were 408 (98 Gonorrhoea, 310 Chlamydia) detected infections in the 2012 period and 404 (121 Gonorrhoea, 283 Chlamydia) in 2014. Between 2012 and 2014, the rate of detected extra-genital Chlamydia/Gonorrhoea infections increased 4-fold from 18/408, 4.4\% to 77/404 19\% (P < $0.0001)$. The rise was seen in both pharyngeal $(10 / 408,2.45 \%$ vs $48 / 404,11.8 \% \mathrm{P}<0.0001)$ and rectal infections $(8 / 408,2 \%$ vs $40 / 404,9.9 \%, P<0.0001)$. Significant rises were seen in MSM in rectal $(5 / 408,1.2 \%$ vs $28 / 404,6.9 \% \mathrm{P}<0.0001)$ and pharyngeal infection $(10 / 408,2.5 \%$ vs $21 / 404,5.2 \%, \mathrm{P}=0.02)$ and for women in rectal $(3 / 408,0.7 \%$ vs $12 / 404,3 \% \mathrm{P}<0.02)$ and pharyngeal infection $(0 / 408,0 \%$ vs $20 / 404,5 \%, \mathrm{P}<$ 0.0001). In these patients, rates of extra-genital self-swabbing rose from $0 \%(0 / 24)$ to $58.5 \%(141 / 241), \mathrm{P}<0.0001$. In separate samples of consecutive un-infected patients having extra-genital swabs, self-swabbing rose from $0 \%(0 / 100)$ to $90 \%$ (90/100) $\mathrm{P}<0.0001$.

Conclusion The introduction of routine self -taken extra-genital swabs has led to a large rise in detected extra-genital Chlamydia and/or Gonorrhoea infection, especially for MSM and women. The rise in rates of extra-genital self-swabbing shows that this is acceptable and effective.

\section{P134 CHAPERONES FOR INTIMATE EXAMINATIONS IN A GENITOURINARY MEDICINE CLINIC: AUDIT OF DOCUMENTATION}

${ }^{1}$ Nathan Griffiths, ${ }^{2}$ Cara Saxon, ${ }^{2}$ Sameena Ahmad*. ${ }^{1}$ University of Manchester, Manchester, UK; ${ }^{2}$ University Hospital South Manchester, Manchester, UK

\subsection{6/sextrans-2015-052126.177}

Introduction BASHH, GMC, RCP and FSRH provide guidance stating that a chaperone should be offered for intimate examinations and the name of the chaperone should be documented. Record keeping is often found to be suboptimal in litigation. Our proformas have prompts for both offer and name of chaperone.

Aim/objectives To audit our documentation of chaperone offer (including name) for intimate examinations.

Methods 20\% case notes for new episodes seen by doctors May-July 2014 were randomly selected and reviewed. Gender of doctor and patient were recorded.

Results 208 case notes were examined. 114 patients were examined (61 not examined; 33 inadequate documentation). 96/114 $(84.2 \%)$ had the offer of a chaperone documented; 18 (15.8\%) did not. Of the 96 where the chaperone was documented as offered, 89 (93\%) had the chaperone's name documented; $7(7 \%)$ did not. In 64 cases, doctor and patient were the same gender, and in 50 cases they were opposite gender - chaperone offer was documented in $87.5 \%$ and $80 \%$ respectively ( $p=0.278$, student's 2 tailed t-test).

Discussion Chaperones for intimate examinations reassure and protect both doctors and patients. With the GMC dealing with just under 30 allegations in 2014 recording of this is potentially pivotal. Despite prompts, only $78 \%$ had both offer and name documented. It was concerning that in 33 cases it was not clear as to whether or not an examination had occurred. The results ran counter to expectations with offer of a chaperone higher when patient and doctor were the same gender although this was non-significant.

\section{P135 A MULTI-DISCIPLINARY APPROACH TO FGM REPORTING AND SAFEGUARDING ASSESSMENTS IN THE GUM CLINIC}

Jennifer Leighton, Vian Shafiq, Claire Whitfield, Margaret Kingston*. Central Manchester University Hospitals NHS Foundation Trust, Manchester, UK

\subsection{6/sextrans-2015-052126.178}

Background/introduction Around 103,000 women aged 15-49 in England and Wales are living with the consequences of female genital mutilation (FGM), which has no clinical benefits and is illegal in the UK. Despite this, girls in some communities in the UK continue to have this procedure performed. Mandatory national reporting of FGM cases was introduced in September 2014 and support and safeguarding assessments are required.

Aim(s)/objectives To produce a clinic policy for appropriate assessment of women with FGM.

Methods GUM clinic staff worked with our trust FGM lead, local social services, community paediatric colleagues and support organisations to develop a policy for women with FGM. This incorporates both the mandatory reporting and safeguarding assessment.

Results A clinic proforma for assessing women with FGM was developed to enable clinic staff to follow the new policy. This was introduced following training in November 2014 and we have piloted it since then. To date this has been used to assess 6 women who had undergone FGM; all were black African and one was unaware that she had "been cut". Three women had had type 3 FGM performed, two type 2 and one type 1. Four women reported symptoms as a result of FGM and five stated that they were "against" the procedure. No safeguarding issues were identified.

Discussion/conclusion Whilst implementing the mandatory reporting required for women who have been subjected to FGM, we have successfully developed and implemented a new policy to ensure that appropriate safeguarding assessments are made within the clinic.

\section{P136 SERVICE EVALUATION OF CARE NEEDS OF YOUNG PEOPLE AGED UNDER 25 LIVING WITH HIV: ARE THEY CONSISTENT?}

${ }^{1}$ Siew Yan Teo, ${ }^{1}$ Jennifer Murira*, ${ }^{2}$ Rachel Notman, ${ }^{1}$ Amy Evans. 'Leeds Teaching Hospitals, Leeds, UK; ${ }^{2}$ Department of Clinical and Health Psychology, Leeds, UK

\subsection{6/sextrans-2015-052126.179}

Background/introduction CHIVA standards recommend all adolescents and young people living with HIV have an individualised care plan to transition them to adult services over time, as is appropriate to their age, developmental stage and social circumstances. Within the UK, adolescents living with HIV acquire the infection either via vertical transmission or sexual acquisition. These 2 groups differ in terms of medical, social and psychological needs, with the former group historically doing less well in terms of adherence and prognosis compared to the latter group. $\operatorname{Aim}(\mathrm{s}) /$ objectives To understand and characterise patients under the age of 25 attending for HIV care in a provincial UK adult HIV clinic, and identify care needs.

Methods Case note review of all HIV positive patients attending care under the age of 25 . 